\title{
Performance of Jute (Corchorus olitorius L.) as Relay Crop in Mungbean (Vigna radiata L Wilczek) with Resource Conservation Technology in the Eastern Indo-Gangetic Plains
}

\author{
Benukar Biswas* and Kasturi Ghosh
}

Bidhan Chandra Krishi Viswavidyalaya, Mohanpur, Nadia - 741252, West Bengal, India

*Corresponding author

\section{Keywords \\ Relay cropping, Crop productivity, Jute, Mungbean, Indo-Gangetic plains}

\section{Article Info}

Accepted: 10 December 2018 Available Online: 10 January 2019

\section{A B S T R A C T}

Relay cropping may play an important role for crop productivity and environmental sustainability in modern agriculture if its proper timing of sowing of relay crop system is standardised. A field study was carried out during 2016-17 at the Central Research Farm of the Bidhan Chandra Krishi Viswavidyalaya with seven treatments where jute as relay crop (sown in between 15, 20, 25, 30, 35 days old mungbean) was compared with sole jute and sole mungbean. Jute equivalent yield of the relay crops was $81 \%$ and $74 \%$ higher than sole jute and sole mungbean when jute was sown on in between lines of 15 days old mungbean. This was $78 \%$ and $71 \%$ higher when jute sown on 20 day after mungbean sowing than sole jute and sole mungbean, respectively. Net returns in relay crops sown 15 and 20 DAS mungbean were $144 \%$ and $129 \%$ higher respectively than that of sole jute. Relay system when jute sown at 15 DAS of mungbean was the most energy use efficient system (EUE Econ. - 6.06 and EUE Biol. - 7.14) followed by when jute sown at 20 DAS of mungbean (EUE Econ. - 5.12 and EUE Biol. - 6.79). The highest LER (1.69) was observed in sowing jute after 15 DAS along with $13 \%$ weed smothering efficiency followed by when jute is sown after 20 DAS with 1.64 LER and $21 \%$ weed smothering efficiency. Just after Norwester rain, mungbean can be sown in line and subsequently jute can be sown in between the lines of mungbean after 15-20 DAS on the same field as relay crop for higher system productivity and return owing to low weed incidence in jute, higher organic matter addition from mungbean straw and shaded jute leaf, cost reduction in jute on land preparation and weeding. This remunerative and ecologically beneficial relay system could have the potential to economise jute production cost and to increase the pulse production in the existing jute areas of upland and medium land situation of Eastern IGP.

\section{Introduction}

Jute as environment friendly natural fibre is gaining international attention. Successful quality fibre production depends on cost effective less labour requiring weed management in the Indo-Gangetic Plain (IGP) of India and Bangladesh, the major jute area of the world. In this region, farmers used to grow different pulses in residual moisture after long duration winter rice. This pulse area drastically reduced after introduction of short 
duration high yielding summer season rice and wheat (Biswas et al., 2006). To recover the pulses area and to arrest yield loss due to weed in jute with cultural manipulations the present field experiment was undertaken to find possibility growing jute as relay crop in mungbean.

\section{Materials and Methods}

The field study was carried out during 201617 at the Central Research Farm of the Bidhan Chandra Krishi Viswavidyalaya (tropical subhumid, $1560 \mathrm{~mm}$ annual rainfall, Latitude $22^{0} 58^{\prime} \mathrm{N}$, Longitude $88^{0} 51 / \mathrm{E}$ altitude $9.75 \mathrm{~m}$ amsl, sandy loam soil, aeric Haplaquept, $\mathrm{pH}$ 6.75 , organic carbon $5.4 \mathrm{~g} \mathrm{~kg}^{-1}$, available $\mathrm{N} 85$ $\mathrm{kg} \mathrm{ha}^{-1}, \mathrm{P}_{2} \mathrm{O}_{5} 15.3 \mathrm{~kg} \mathrm{ha}^{-1}$ and $\mathrm{K}_{2} \mathrm{O} 40 \mathrm{~kg} \mathrm{ha}^{-1}$ ) The experiment was laid out in randomised complete block design with seven treatments. Jute as relay crop (sown in between 15, 20, 25, 30,35 days old mungbean) was compared with sole jute and sole mungbean on the basis of weed flora dynamics, productivity, profitability and land use efficiency.

\section{Results and Discussion}

Jute can be successfully grown as relay crop in mungbean if sown within 15-20 DAS of mungbean. Jute fails to stand due to smothering effect of mungbean if sown after 30 DAS of mungbean sowing. Jute equivalent yield of the relay crops was $81 \%$ and $74 \%$ higher than sole jute and sole mungbean when jute was sown on in between lines of 15 days old mungbean. This was $78 \%$ and $71 \%$ higher when jute sown on 20 day after mungbean sowing than sole jute and sole mungbean, respectively. Mungbean crop residue resulted higher carbon sequestration which encourage higher microbial activity and enhanced nutrient availability as reported by Ghosh et al., 2012.

Net returns in relay crops sown 15 and 20 DAS mungbean were $144 \%$ and $129 \%$ higher respectively than that of sole jute. Energy use efficiency in relay crops sown 15 and 20 DAS mungbean were $144 \%$ and $129 \%$ higher respectively than that of sole jute. BCR are also higher in relay systems followed by broadcasted jute.

Relay system when jute sown at 15 DAS of mungbean was the most energy use efficient system (EUE Econ. - 6.06 and EUE Biol. 7.14) followed by when jute sown at 20 DAS of mungbean (EUE Econ. - 5.12 and EUE Biol. - 6.79).

This relay system was efficient in smothering of weeds of jute and land use also. The highest LER (1.69) was observed in sowing jute after 15 DAS along with $13 \%$ weed smothering efficiency followed by when jute is sown after 20 DAS with 1.64 LER and $21 \%$ weed smothering efficiency (Fig. 1, 2 and Table 1).

Table.1 Weed smothering efficiency and Land equivalent ratio of mungbean - jute relay system in the Eastern IGP

\begin{tabular}{|c|c|c|c|}
\hline Treatment & \multicolumn{2}{|c|}{ Weed smothering efficiency (\%) } & LER \\
\hline & 21 DAS & 42 DAS & \\
\hline Sowing of jute at 15 DAS of mungbean & 13 & 38 & 1.69 \\
\hline Sowing of jute at 20 DAS of mungbean & 21 & 44 & 1.64 \\
\hline Sowing of jute at 25 DAS of mungbean & 28 & 68 & 1.13 \\
\hline CD (5\%) & 5 & 7 & 0.13 \\
\hline
\end{tabular}


Fig.1 Yield and economics of mungbean-jute relay system
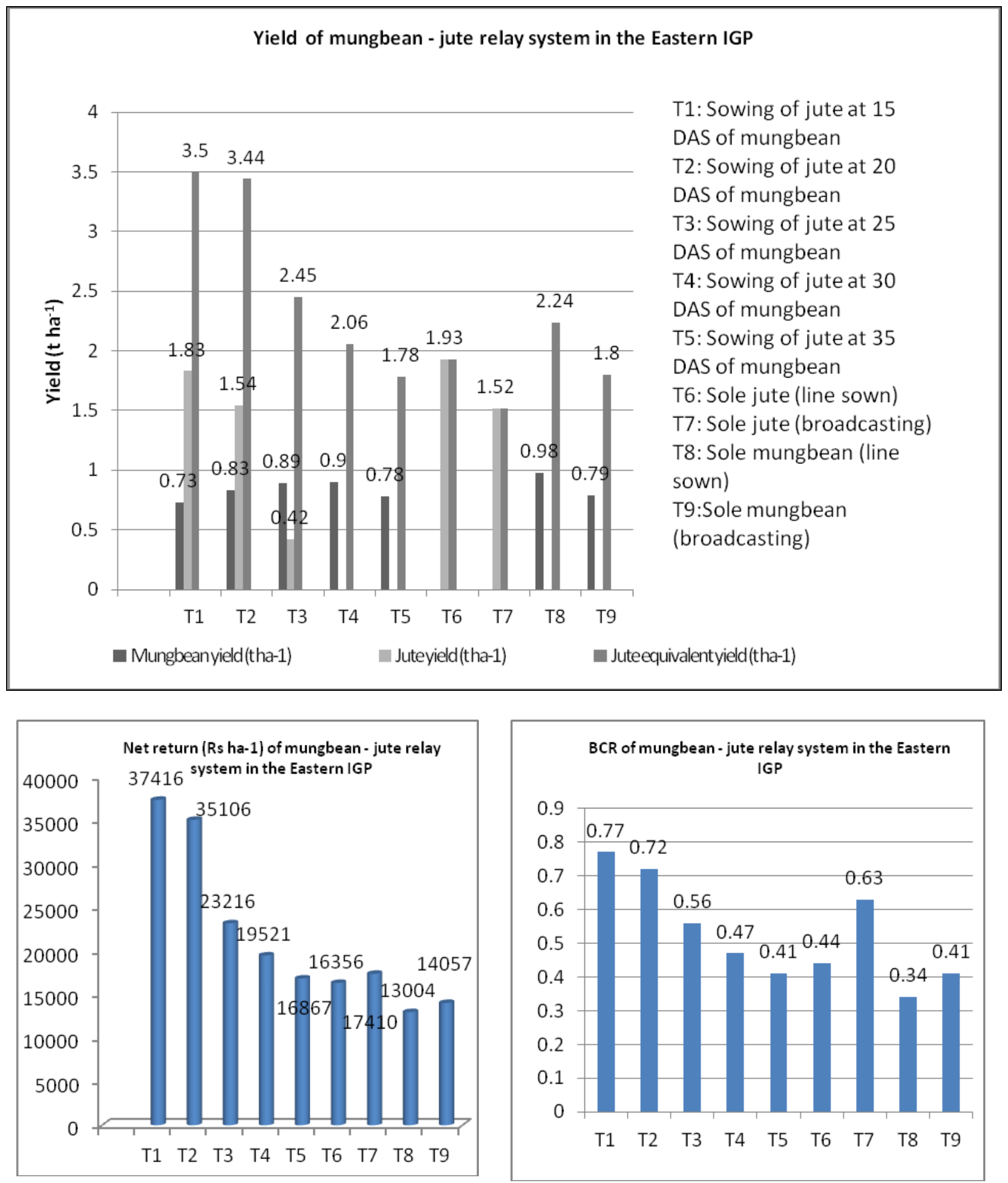
Fig.2 Energy use efficiency of mungbean-jute relay system

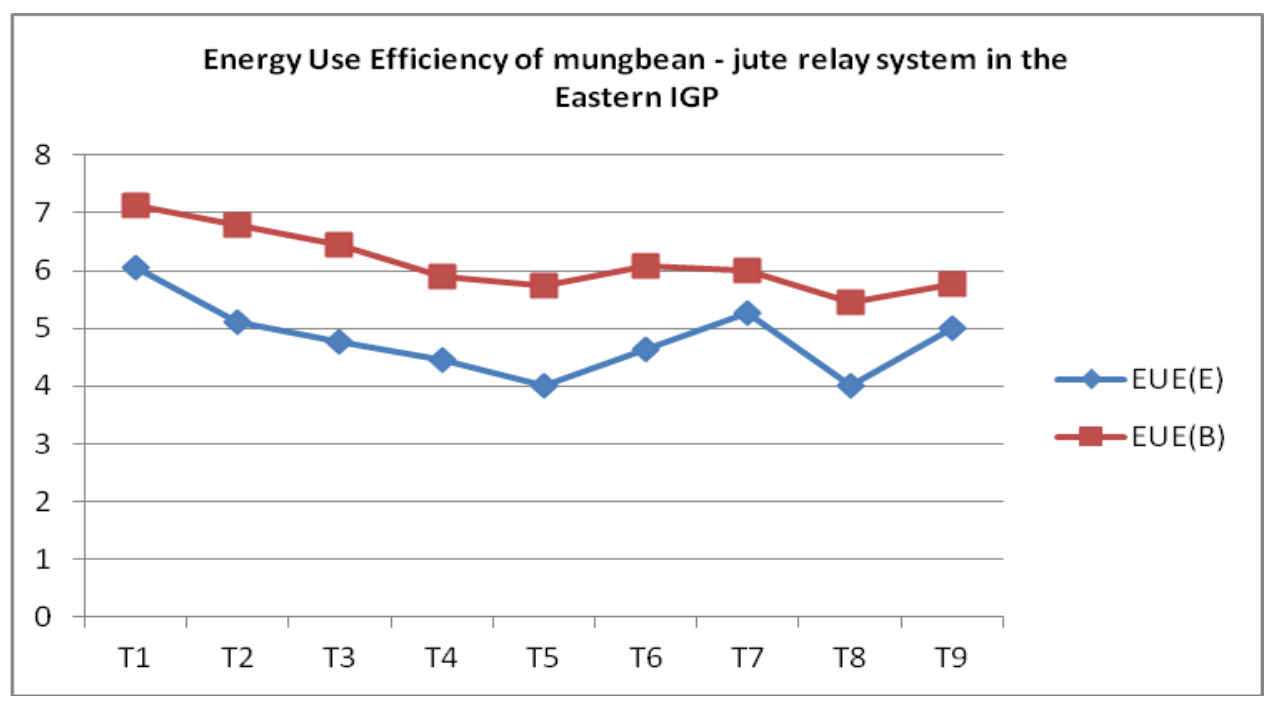

Pooled analysis over 2014-2015 reflects significantly higher yield, net return, BCR, energy use efficiency, land equivalent ratio in relay system than either sole jute or sole mungbean. The performance of the relay system when jute sown at 15 DAS of mungbean was better than that when jute sown at 20 DAS of mungbean.

In conclusion, just after Norwester rain, mungbean can be sown in line and subsequently jute can be sown in between the lines of mungbean after 15-20 DAS on the same field as relay crop for higher system productivity and return owing to low weed incidence in jute, higher organic matter addition from mungbean straw and shaded jute leaf, cost reduction in jute on land preparation and weeding. This remunerative and ecologically beneficial relay system could have the potential to economise jute production cost and to increase the pulse production in the existing jute areas of upland and medium land situation of Eastern IGP. However, further research on water management in especially to mitigate early drought condition and further fine tuning for the possibility of resource conservation technology in this relay system need to be explored.

\section{References}

Biswas, B., Ghosh, D. C., Dasgupta, M. K., Trivedi, N., Timsina, J. And Dobermann, A. 2006. Integrated assessment of cropping systems in the Eastern Indo-Gangetic plain. Field Crop Research 99: 35-47.

Ghosh, S., Wilson, B., Ghosal, S., Senapati, N. And Mandal, B. 2012. Organic amendments influence soil quality and carbon sequestration in the IndoGangetic plains of India. Agriculture, Ecosystems \& Environment. 156: 134141.

\section{How to cite this article:}

Benukar Biswas and Kasturi Ghosh. 2019. Performance of Jute (Corchorus olitorius L.) as Relay Crop in Mungbean (Vigna radiata L Wilczek) with Resource Conservation Technology in the Eastern Indo-Gangetic Plains. Int.J.Curr.Microbiol.App.Sci. 8(01): 941-944.

doi: https://doi.org/10.20546/ijcmas.2019.801.102 